Article

\title{
Facile Fabrication of Metal Oxide Based Catalytic Electrodes by AC Plasma Deposition and Electrochemical Detection of Hydrogen Peroxide
}

\author{
Quang-Tan Bui ${ }^{1}$, In-Keun $\mathrm{Yu}^{2}$, Anantha Iyengar Gopalan ${ }^{3} \oplus$, Gopalan Saianand ${ }^{4} \oplus$, \\ Woonjung Kim ${ }^{1, *}$ and Seong-Ho Choi ${ }^{1, *(1)}$ \\ 1 Department of Chemistry, Hannam University, Daejeon 34054, Korea; buiquangtan.bka@gmail.com \\ 2 Plasma Technology Research Center, National Fusion Research Institute (NFRI), Gunsan 54004, Korea; \\ ikyu@nfri.re.kr \\ 3 Daeyong Regional Infrastructure Technology Development Center, Kyungpook National University, \\ Daegu 41556, Korea; algopal99@gmail.com \\ 4 School of Engineering, Faculty of Engineering and Built Environment, The University of Newcastle, \\ Callaghan, NSW 2308, Australia; Saianand.Gopalan@newcastle.edu.au \\ * Correspondence: wjkim@hnu.kr (W.K.); shchoi@hnu.kr (S.-H.C.); \\ Tel.: +82-42-629-8939 (W.K.); +82-42-629-8824 (S.-H.C.)
}

Received: 11 October 2019; Accepted: 22 October 2019; Published: 25 October 2019

\begin{abstract}
In this study, the fabrication of a metal oxide nanoparticles (NPs) dispersed catalytic electrode is described based on a new alternating current (AC) plasma deposition approach. The fabrication involves the treatment of AC plasma on a precursor solution comprised of metal salts such as $\mathrm{CuCl}_{2}$, $\mathrm{FeCl}_{2}$, and $\mathrm{ZnCl}_{2}$, and a monomer (acrylic acid) in the presence/absence of a cross-linker. Furthermore, the utility of such developed electrodes has been demonstrated for the electrochemical determination of hydrogen peroxide $\left(\mathrm{H}_{2} \mathrm{O}_{2}\right)$. The electrode materials obtained through plasma treatment was characterized by Fourier transform infrared (FT-IR) spectroscopy, scanning electron microscope (SEM), contact angle measurements, energy-dispersive X-ray spectroscopy (EDS), X-ray photoelectron spectroscopy (XPS), and cyclic voltammetry. Among the metal oxide modified electrodes prepared by the AC plasma deposition method, the copper oxide $(\mathrm{CuO})$ NPs catalytic electrode exhibited significant oxidation and reduction peaks for $\mathrm{H}_{2} \mathrm{O}_{2}$ in phosphate-buffered saline solution. The catalytic electrode with $\mathrm{CuO}$ NPs exhibited a combination of good $\mathrm{H}_{2} \mathrm{O}_{2}$ sensing characteristics such as good sensitivity (63.52 $\left.\mathrm{mA} \mathrm{M}^{-1} \mathrm{~cm}^{-2}\right)$, good selectivity, low detection limits $(0.6 \mu \mathrm{M})$, fast sensing response $(5 \mathrm{~s})$, a wide linear range $(0.5-8.5 \mathrm{mM})$, and good stability over 120 cycles. Based on our results, it is well demonstrated that plasma deposition could be effectively utilized for the fabrication of the catalytic electrode for detection of $\mathrm{H}_{2} \mathrm{O}_{2}$ concentrations. Further, the strategy of using AC plasma for fabrication of metal oxide-based modified electrodes could also be extended for the fabrication of other kinds of nanomaterials-based sensors.
\end{abstract}

Keywords: catalytic electrode; plasma deposition; hydrogen peroxide; $\mathrm{CuO}$; sensor performances

\section{Introduction}

Hydrogen peroxide $\left(\mathrm{H}_{2} \mathrm{O}_{2}\right)$ is a green oxidant that is widely used in various fields [1,2]. In addition, $\mathrm{H}_{2} \mathrm{O}_{2}$ can be used as an oxidizing agent for fuel cells, and in various commercial products, such as cosmetics and medicine [3]. Recently, $\mathrm{H}_{2} \mathrm{O}_{2}$ has attracted research attention as an important by-product of enzyme reactions in the field of biotechnology [4]. Among the various $\mathrm{H}_{2} \mathrm{O}_{2}$ detection techniques that have been developed, which include spectrometry, fluorescence, and chromatography, the electrochemical methods offer special combinational advantages like low detection limit, high 
selectivity, and high sensitivity [5-10]. It must be noted that a variety of electrochemical $\mathrm{H}_{2} \mathrm{O}_{2}$ sensors reported in literature are predominantly based on enzymes. Knowing the intrinsic disadvantages of enzyme-based electrochemical sensors, non-enzymatic $\mathrm{H}_{2} \mathrm{O}_{2}$ sensors are receiving considerable interest in recent years due to their advantages such as low cost, high stability, prompt response, ultra-low detection limit, and excellent sensitivity. Non-enzymatic electrochemical $\mathrm{H}_{2} \mathrm{O}_{2}$ sensors are designed based on $\mathrm{H}_{2} \mathrm{O}_{2}$ electro-oxidation/electroreduction and thus require electrocatalytic materials. Therefore, development of new electrode materials with high catalytic activity and catalytic stability is continuously being given priority and utmost importance.

Several metal oxide nanostructures [11-17] have been utilized to modify the surface of electrodes and were demonstrated to exhibit excellent redox capabilities towards detection of $\mathrm{H}_{2} \mathrm{O}_{2}$ with high reaction activity, catalytic efficiency, strong absorption ability, and low cost $[18,19]$. Particularly, copper oxide $(\mathrm{CuO})$ has been extensively used in non-enzymatic electrochemical sensors, due to its excellent electrochemical properties (proper redox potentials), catalytic properties (enhanced reaction rate, weak adsorption of hydrogen species etc.), ease of preparation, and low cost [20]. One must note that different methodologies were utilized for the preparation of $\mathrm{CuO}$ nanostructures while fabricating these electrocatalytic electrodes. For instance, the electrochemical behavior of $\mathrm{H}_{2} \mathrm{O}_{2}$ was studied using a $\mathrm{CuO}$ nanorod-modified electrode and a detection limit of $0.22 \mu \mathrm{M}$ was reported [21]. The fabrication of an electrocatalytic electrode involves a two-stage method for the preparation of the $\mathrm{CuO}$ nanorod and dispensing the solution of it on the electrode surface. $\mathrm{CuO}$ nanoleaf electrodes exhibited an excellent non-enzymatic response to $\mathrm{H}_{2} \mathrm{O}_{2}$ [22]. Wang et al. prepared hollow $\mathrm{CuO}$ particles using the electrospinning method and the modified the carbon paste electrodes were used for the electrochemical $\mathrm{H}_{2} \mathrm{O}_{2}$ detection [23]. $\mathrm{Xu}$ et al. synthesized $\mathrm{Cu}_{2} \mathrm{O}-\mathrm{rGO}$ nanocomposites through three different methods and demonstrated that the $\mathrm{Cu}_{2} \mathrm{O}-\mathrm{rGO}$ nanocomposites exhibited superior $\mathrm{H}_{2} \mathrm{O}_{2}$ detection with excellent sensor characteristics, such as a wider linear range (0.03-12.8 mM), higher sensitivity $\left(19.5 \mathrm{~mA} \mathrm{mM}^{-1}\right)$, and better stability [24]. Similarly, Zhang et al. synthesized the porous $\mathrm{Cu}_{2} \mathrm{O}$ nanocubes via a sonochemical method. The fabricated electrode exhibited good electrocatalytic activity for the reduction of $\mathrm{H}_{2} \mathrm{O}_{2}$. A low detection limit $(1.5 \mathrm{mM})$ and high sensitivity $\left(50.6 \mathrm{~mA} \mathrm{mM}^{-1}\right)$ were achieved, which were mainly attributed to its porous structure [25]. Likewise, several other strategies such as pulse laser deposition, screen printing, sol-gel process etc. were used for the deposition of pure metal oxides towards the fabrication of sensors. The sensor performance strongly depends on the method of metal oxide deposition as well as the surface interaction between the metal oxide and the analyte of choice. It becomes essential to select efficient metal oxide formation strategy during the fabrication of electrochemical sensors. The plasma synthesis process has been emerging as one of the most efficient methods for producing quality nanostructured materials [26]. Thin films deposited by plasma deposition are currently used to fabricate several devices, such as electroluminescent displays, magnetic read heads, etc. However, to the best of our knowledge, reports on the preparation of the catalytic metallic oxide-based modified electrodes using plasma deposition and performance evaluation of their electrochemical sensor fabrication for the detection of $\mathrm{H}_{2} \mathrm{O}_{2}$ are scarce.

Plasmas are chemically active media and are termed based on the way that they are activated, as well as through their working power. In a typical plasma-assisted film deposition, a sequence of processes such as exposure of different species present in the plasma, reactive species formation (mostly radicals), and reaction with the surface groups occur and lead to the film deposition. In general, plasma-based film deposition comprises of a reaction-either reduction, or oxidation, or radical formation of the chemisorbed precursor-and the intermediate species are subsequently transformed into film. The plasma synthesis process, that includes physical vapor deposition and chemical vapor deposition, has been effectively used for producing nanostructured metal, metal oxides, and ceramic nanoparticles [26]. At room temperature, high-quality aluminum oxide $\left(\mathrm{Al}_{2} \mathrm{O}_{3}\right)$ films were obtained by plasma-assisted atomic layer deposition using the simple precursors, $\mathrm{Al}\left(\mathrm{CH}_{3}\right)_{3}$ and $\mathrm{O}_{2}$ [27]. Scalable and one-step formation of $\mathrm{ZnO}$ nanorod films was achieved using a radio frequency thermal plasma system through thermal evaporation of different zinc compounds [26]. Atmospheric pressure 
plasmas have been used to grow polymer films on different substrates [28]. Tungsten-doped TiOx nanoparticles (NPs) were obtained through the modification of commercially available $\mathrm{TiO}_{2} \mathrm{NPs}_{\mathrm{N}}$ using plasma processing [29]. Tungsten trioxide NPs were synthesized by microwave plasma treatment [30]. Polyacrylic acid (PAA) has been widely used in a variety of applications including sensors due to its super hydrophilic properties, biocompatibility and biodegradability [31]. O'Hare et al. developed organic coatings with a deposition rate of $40 \mathrm{~nm} \mathrm{~min}^{-1}$ by deposition of PAA from an acrylic acid (AA) monomer through the post-discharge of a radio frequency helium plasma [32]. In the same way, Nisol et al. used a dielectric barrier discharge process to prepare plasma-polymerized PAA films by nebulizing the precursor in a helium plasma [33]. The helium and organic precursor flow rates were found to influence the fragmentation of the AA monomer and the presence of carbonyl groups in the coatings [34]. However, to the best of our knowledge, this is the first report on the simple fabrication of an electrochemical sensor using a one-step AC plasma deposition of PAA and metal oxide over the surface of an indium tin oxide (ITO) electrode.

In this study, we fabricated the metal oxide NPs-PAA composite loaded catalytic electrode by AC plasma deposition using the precursors, AA (monomer for PAA), and metal salts $\left(\mathrm{CuCl}_{2}\right.$, $\mathrm{FeCl}_{2}$, and $\mathrm{ZnCl}_{2}$ ). After the plasma treatment, the electrode surface is expected to contain PAA through polymerization of AA and respective metal oxides via reduction of metal halides. The fabricated catalytic electrodes, comprised of metal oxide-PAA film, were used for the non-enzymatic electrochemical detection of $\mathrm{H}_{2} \mathrm{O}_{2}$. Initially, the as-developed catalytic materials and electrodes were characterized for relevant physico-chemical properties. The sensor studies were designed in two parts: i) an initial evaluation of all the metal oxide catalyst-modified electrodes towards assessing the electrocatalytic activity, and ii) in-depth studies on the sensor performance evaluation for the best selected electrode. Briefly, $\mathrm{CuONPs}$ catalytic electrodes were evaluated for the electrochemical detection of $\mathrm{H}_{2} \mathrm{O}_{2}$. The sensing concentration range, selectivity, and stability of the fabricated electrode CuO NPs catalytic electrodes are reported. The sensor results are explained based on a plausible mechanism.

\section{Results}

Keeping the objective that plasma treatment can be used to modify the electrode surface, we demonstrated the feasibility of fabricating catalytic electrodes from the precursors containing a polymerizable monomer and the metal salt, through in-situ simultaneous generation of polymer and metal oxide. Typically, AA was chosen as the precursor for polymer and metal halides $\left(\mathrm{CuCl}_{2}, \mathrm{FeCl}_{2}\right.$, and $\mathrm{ZnCl}_{2}$ ) for metal oxide formation. The deposition of carboxylic acid-rich polymer (PAA in this case) coating causes the electrode surface to become hydrophilic, which facilitates the aqueous electrochemical reactions. Metal oxide electrocatalysts [35] have been successfully utilized for a variety of electrochemical reactions; particularly, metal oxide nanostructured modified electrodes have been demonstrated to possess excellent reduction/oxidation capabilities, and these characteristics were used for the detection of $\mathrm{H}_{2} \mathrm{O}_{2}$ [36]. The plasma-based formation of metal oxide is known [37]. In this work, we have demonstrated the utilization of plasma treatment for the fabrication of catalytic electrodes, comprised of copper or iron or zinc oxide as the catalytic material. After characterization and further evaluation of electrocatalytic efficiency of the modified electrodes, the best modified electrode was further used for the non-enzymatic electrochemical detection of $\mathrm{H}_{2} \mathrm{O}_{2}$.

\subsection{Characterization of the Catalytic Electrode Prepared by AC Plasma Deposition}

\subsubsection{Contact angle and Wettability}

Figure 1 presents the water contact angle (CA) of the various ITO-modified electrodes (obtained by the AC plasma deposition method) and the bare ITO. From a simple examination of the CA values, one can notice that the bare ITO electrode has the largest CA of $75.5^{\circ}$ (Figure 1). The CA of PAA/ITO, $\mathrm{CuO} / \mathrm{ITO}, \mathrm{Fe}_{2} \mathrm{O}_{3} / \mathrm{ITO}$ and $\mathrm{ZnO} / \mathrm{ITO}$ electrodes were $33.6^{\circ}, 55.5^{\circ}, 42.2^{\circ}$ and $36.4^{\circ}$, respectively (Figure 1 ). As can be seen, the original ITO glass is relatively hydrophobic with a high CA. Compared to original 
ITO glass, the CAs of the fabricated catalytic electrode were significantly lower. Wettability of any solid surface, electrode surface in this case, is significantly influenced by the surface characteristics such as chemistry, charge, hydrophilicity, topography, and roughness. Among the different factors, surface energy and surface roughness are expected to play dominant roles. There are two modifying components in the surface of the modified electrode, namely metal oxide and PAA. We hypothesize that the variations in the surface heterogeneity or roughness could influence the CA by changing at the point along the three-phase (solid-liquid-air) contact line. It is expected in the first principle that the hydrophilic groups (carboxylic groups (-COOH)) from PAA and the relatively hydrophillic metal oxide in different proportions in these modified electrode surfaces affect the CA on the film. A simple clue is evident from the CA measurement that the modified electrode surface is relatively hydrophilic compared to the bare electrode surface (ITO).

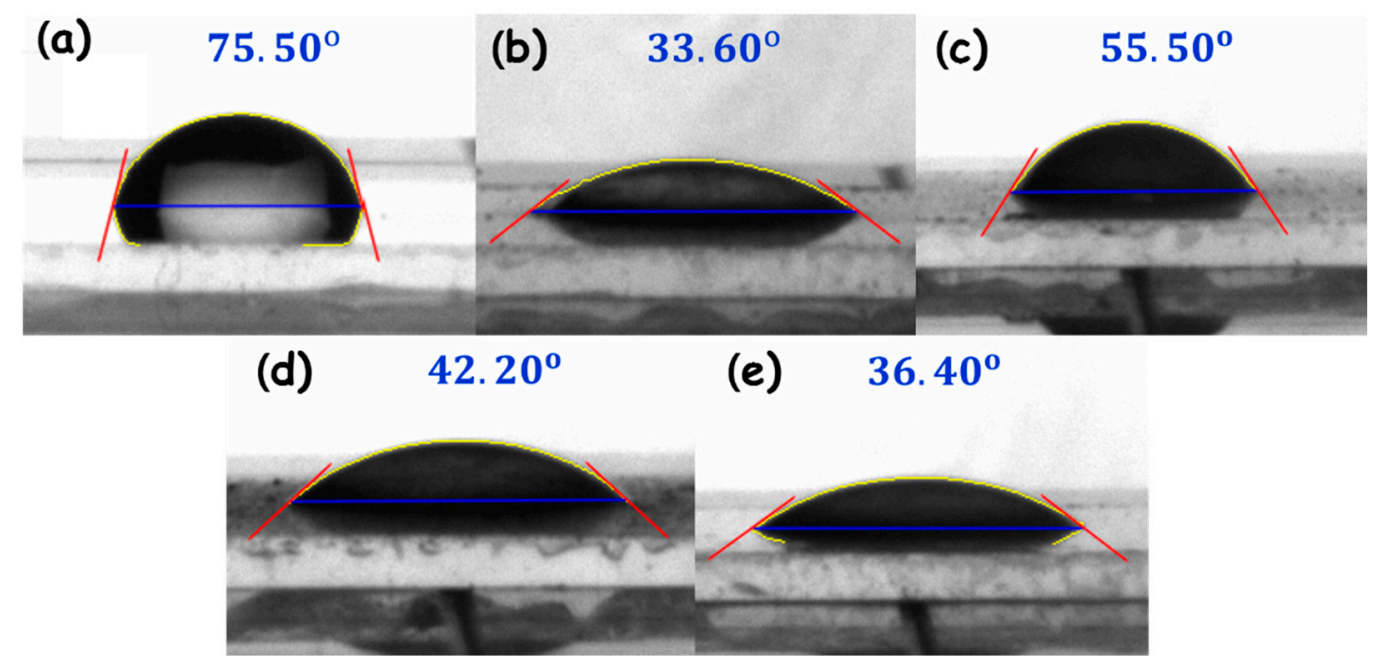

Figure 1. Contact angles of (a) bare indium tin oxide (ITO), (b) polyacrylic acid (PAA), (c) CuO-PAA, (d) $\mathrm{Fe}_{2} \mathrm{O}_{3}-\mathrm{PAA}$ and (e) $\mathrm{ZnO}-\mathrm{PAA}$ coated on ITO electrode.

\subsubsection{Scanning Electron Microscopy (SEM)}

Figure 2 displays the SEM image of the bare ITO electrode and the other modified electrodes. The surface of the bare ITO is uniform as well as smooth (Figure 2a). The PAA-coated ITO surface retains the smoothness implying the uniform coating of PAA onto the entire ITO surface (Figure $2 b$ ). Figure 2c-e show the SEM images of $\mathrm{CuO}-\mathrm{PAA}, \mathrm{Fe}_{2} \mathrm{O}_{3}-\mathrm{PAA}$ and $\mathrm{ZnO}-\mathrm{PAA}$ modified ITO electrodes. The electrode surfaces became rough and non-uniform because of the inclusion of metal oxide particles within the PAA matrix during plasma-induced simultaneous polymerization and metal oxide formation. The $\mathrm{N}, \mathrm{N}^{\prime}$-methylenebisacrylamide (MBA) cross-linked PAA network film surface has a different morphology than PAA coated ITO surface. The ITO/PAA (MBA) surface appears to have an interconnected worm like morphology with a rough morphology (Figure 3a). A typical image for the metal oxide included PAA (MBA) is shown in Figure 3b. The morphology of $\mathrm{CuO}$ included PAA (MBA) (Figure 3b) informs the presence of more dense and compact surface as compared to CuO-PAA (Figure 3a) modified surface with a few randomly distributed larger sized particles on the surface.

On comparing the energy-dispersive X-ray spectroscopy (EDS) data of ITO and ITO/PAA, ITO/metal oxide dispersed polymer electrode surfaces, one can notice that ITO/metal oxide dispersed polymer electrode surfaces contained the additional presence of respective metal (copper, zinc and iron) signals representing the metal oxides along with carbon and oxygen arising from the polymer structure (Supplementary materials, Figure S1). 


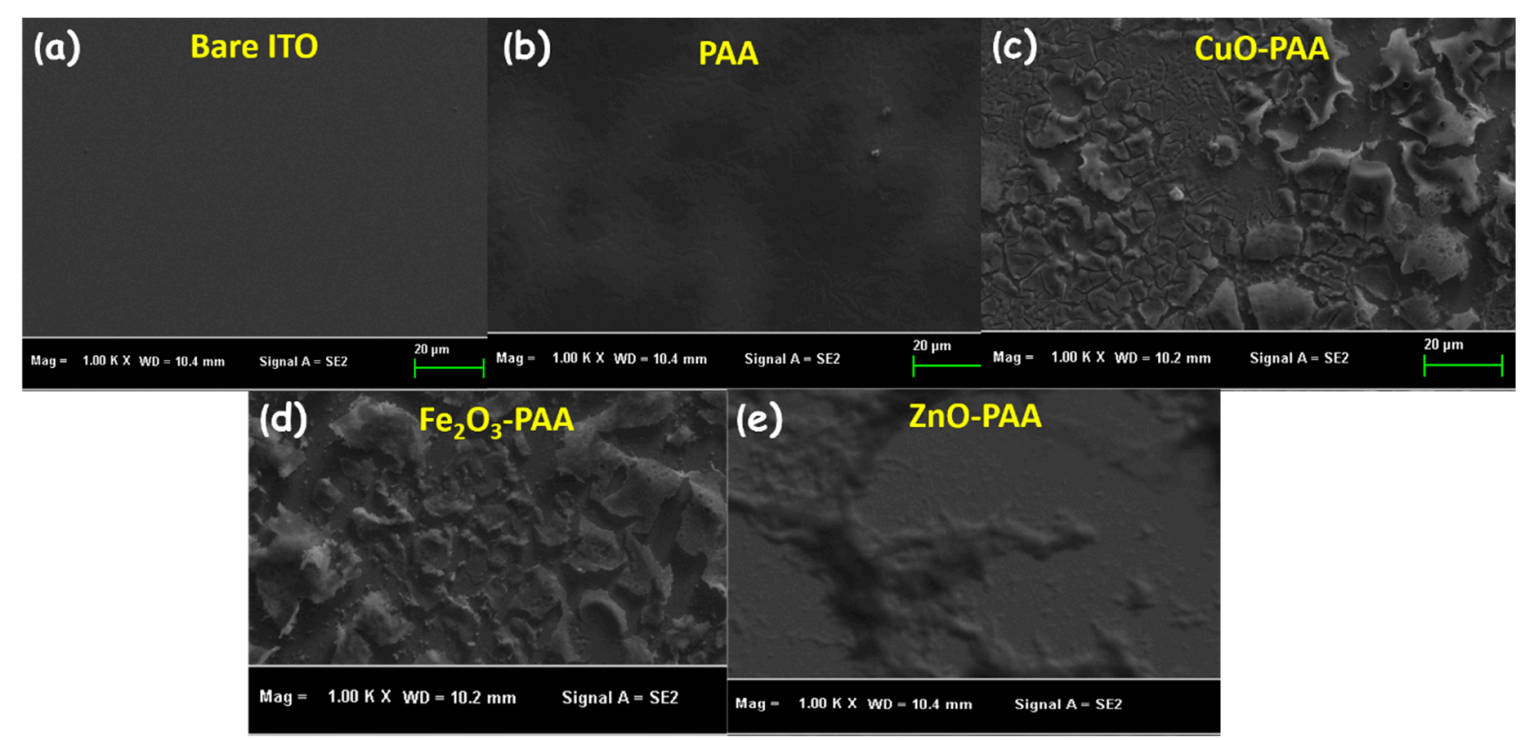

Figure 2. Scanning electron microscopy (SEM) images of (a) bare ITO, (b) PAA, (c) CuO-PAA, (d) $\mathrm{Fe}_{2} \mathrm{O}_{3}-\mathrm{PAA}$ and (e) $\mathrm{ZnO}-\mathrm{PAA}$ coated on ITO.

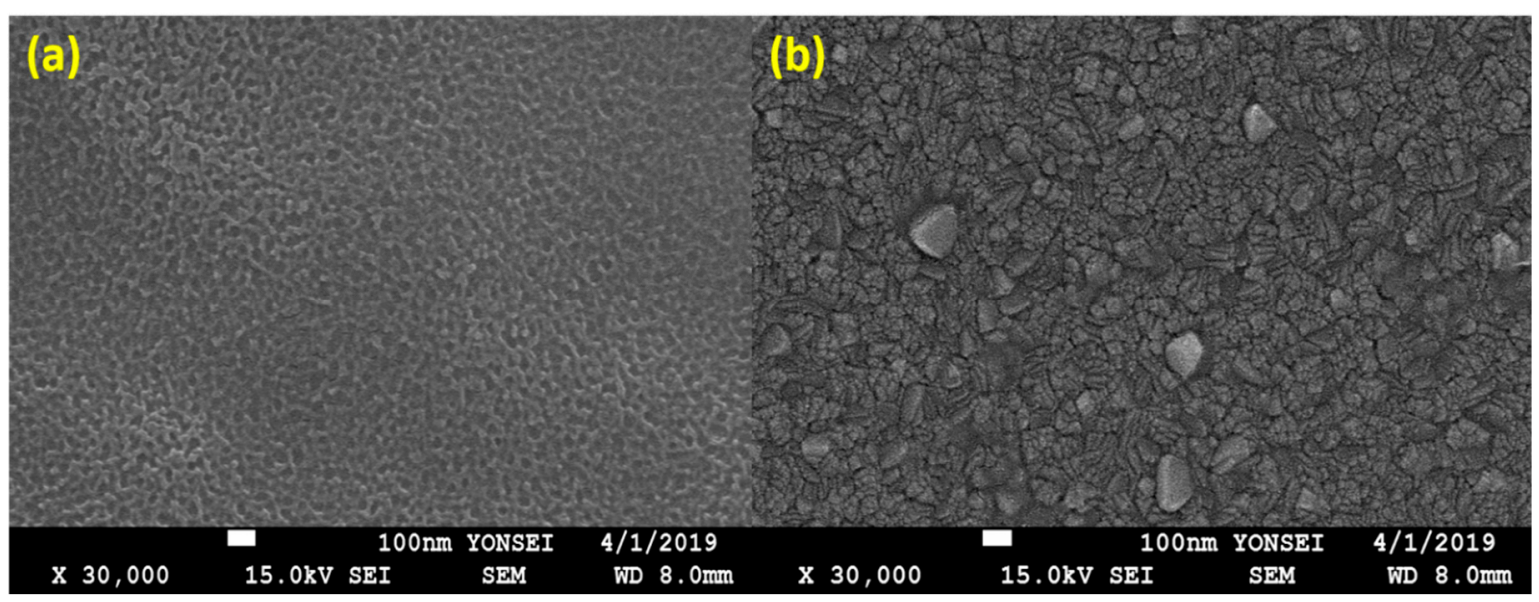

Figure 3. FE-SEM images of (a) N,N'-methylenebisacrylamide (MBA)-PAA/ITO and (b) CuO-MBAPAA/ITO electrode.

\subsubsection{Microstructure Analysis}

X-ray photoelectron spectroscopy (XPS) survey spectra of the various fabricated electrodes by AC plasma deposition are presented in Supplementary Materials, Figures S2 and S3. The survey spectra of all modified electrodes show the peak of the $\mathrm{C} 1 \mathrm{~s}$, at $291.2 \mathrm{eV}$ that originates from the skeletal structure of PAA. Likewise, survey spectra of all modified electrodes show the O1s, peak around $531.8 \mathrm{eV}$ that corresponds to the presence of PAA or co-existence of PAA and metal oxides. In Figures S2 and S3, two peaks could be noticed at $933.4 \mathrm{eV}$ and $953.9 \mathrm{eV}$ for $\mathrm{Cu}$-based PAA-modified electrodes which belong to the binding energies of $\mathrm{Cu} 2 \mathrm{p}_{3 / 2}$ and $\mathrm{Cu} 2 \mathrm{p}_{1 / 2}$. The $\mathrm{Cu}(0), \mathrm{Cu}(\mathrm{I})$ and $\mathrm{Cu}(\mathrm{II})$ states could be distinguished from the binding energy (BE) values [38]. Specifically, the $\mathrm{BE}$ values of $\mathrm{Cu}(0), \mathrm{Cu}(\mathrm{I})$ and $\mathrm{Cu}(\mathrm{II})$ states could be $932.63 \mathrm{eV}, 932.43 \mathrm{eV}$ and $933.51 \mathrm{eV}$. The presence of a higher BE peak $(933.4 \mathrm{eV})$ for $\mathrm{Cu} 2 \mathrm{p}_{3 / 2}$ suggests the existence of $\mathrm{Cu}$ (II) states. Now, there could be two possibilities. The first one is that the $\mathrm{Cu}$ precursor, namely cupric chloride, can be present along with PAA. Alternatively, the $\mathrm{Cu}$ species may be transformed into copper oxide during plasma treatment. We noticed an additional satellite peak around $945.2 \mathrm{eV}$ suggesting the formation of cupric oxide and the occurrence of a partially-filled d9 shell configuration in the ground state for $\mathrm{CuO}$ [39]. Similarly, the presence of $\mathrm{Fe}_{2} \mathrm{O}_{3}$ and $\mathrm{ZnO}$ was evident from the BE peaks, $710.9 \mathrm{eV}$ and $1022.1 \mathrm{eV}$, respectively. 


\subsubsection{Cyclic Voltammetry}

Cyclic voltammetry was used to evaluate the electrochemical performance of the fabricated catalytic electrodes. Cyclic voltammograms (CVs) of these electrodes were recorded in $0.1 \mathrm{M}$ phosphate buffer solution (PBS) $(\mathrm{pH}=7.4)$ for the bare ITO, PAA/ITO electrodes and similarly fabricated metal oxide/PAA modified electrodes. The bare ITO and PAA/ITO electrodes (Figure 4) did not show any electrochemical redox peaks inferring weak electroactivity for the electrodes. However, metal oxide-PAA/ITO electrodes. Figure 4 also displayed redox peaks that correspond to the respective metal oxides. The redox peaks of $\mathrm{Fe}_{2} \mathrm{O}_{3}-\mathrm{PAA} / \mathrm{ITO}$ and $\mathrm{ZnO}-\mathrm{PAA} / \mathrm{ITO}$ electrodes had very low peak current values. On the other hand, CuO-PAA/ITO electrode exhibited a remarkable redox peak current as compared to $\mathrm{Fe}_{2} \mathrm{O}_{3}-\mathrm{PAA} / \mathrm{ITO}$ and $\mathrm{ZnO}-\mathrm{PAA} / \mathrm{ITO}$ electrodes (Figure 4). From these results, we considered the $\mathrm{CuO}-\mathrm{PAA} / \mathrm{ITO}$ modified electrode as the best one amongst the metal oxide-PAA/ITO electrodes prepared in this study. Therefore, we used the $\mathrm{CuO}-\mathrm{PAA} / \mathrm{ITO}$ modified electrode for further electrochemical studies towards the electrochemical detection of $\mathrm{H}_{2} \mathrm{O}_{2}$. However, we could observe that the electrochemical stability of the CuO-PAA/ITO modified electrode was not good enough to proceed for long-time electrochemical measurements because the redox peak current rapidly decayed with the number of potential cycles. We attributed the deterioration of electroactivity of the CuO-PAA/ITO electrode to the leaching of the $\mathrm{CuO}$ from the electrode surface. Hence, we wanted to prevent leaching of $\mathrm{CuO}$ during electrochemical measurements and to have stable anchoring of $\mathrm{CuO}$ onto the surface of the electrode. In the precess of improving the stability of the working electrodes, we tested the electrochemical stability of the CuO-PAA(MAA)/ITO electrode over the long extended potential cycle conditions. The redox currents corresponding to the $\mathrm{CuO}$ did not show significant variation over the long time of cyclic voltammetric measurements. Hence, we selected the CuO-PAA(MAA)/ITO electrode for studying the electrochemical detection of $\mathrm{H}_{2} \mathrm{O}_{2}$.

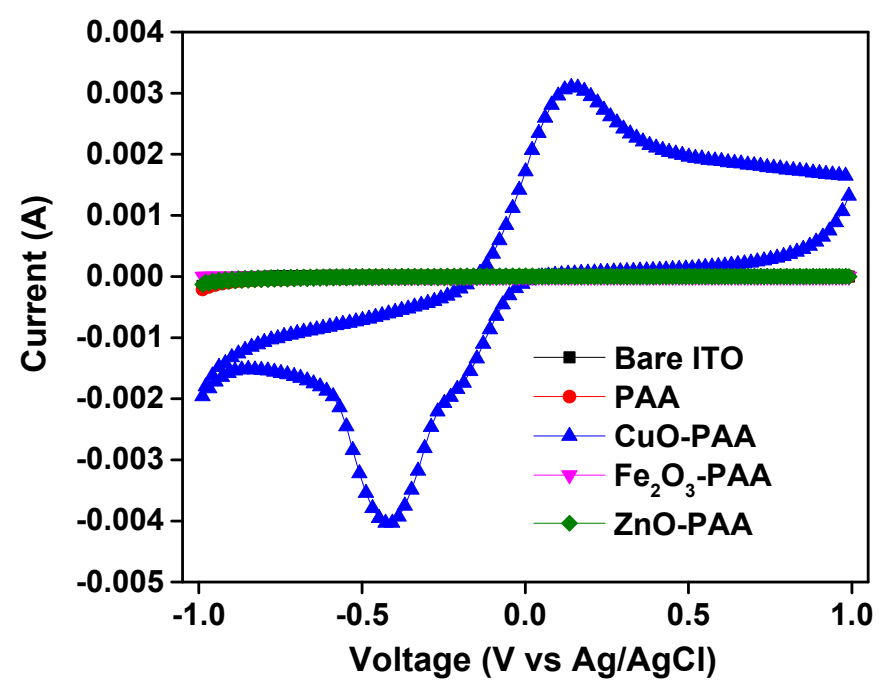

Figure 4. Cyclic voltammograms of the bare ITO, PAA, CuO-PAA, $\mathrm{Fe}_{2} \mathrm{O}_{3}-\mathrm{PAA}$, and $\mathrm{ZnO}-\mathrm{PAA} /$ ITO electrodes.

\subsection{Electrocatalytic Determination of $\mathrm{H}_{2} \mathrm{O}_{2}$}

\subsubsection{Electrode Catalytic Activity}

At the first instance, we recorded the CVs of the CuO-(MBA)PAA/ITO electrode in $0.1 \mathrm{M}$ PBS (pH $=7.4$ ) and compared with CVs of bare ITO and (MBA)PAA/ITO electrodes (Figure 5). The bare ITO and PAA(MBA)/ITO electrodes showed negligible peak currents in the selected potential window as compared to CuO-MBA-PAA/ITO electrode. Particularly, the CuO-(MBA)PAA/ITO electrode showed well-defined oxidation-reduction peaks that corresponded to the oxidation and reduction of $\mathrm{Cu}(\mathrm{I}) / \mathrm{Cu}$ (II) couple. The electrochemical response of the CuO-(MBA)PAA/ITO electrode was quasi-reversible 
with an anodic to cathodic peak separation of $200 \mathrm{mV}$ and an anodic to cathodic peak current ratio of $\sim 0.60$. The deviation from reversibility in terms of peak current ratio is attributed to the possible presence of agglomerated $\mathrm{CuO}$ NPs [40]. The wider anodic to cathodic separation revealed that $\mathrm{Cu}$-based electron transfer processes occur at an insulating polymer matrix, possibly diminishing the rate of the electron transfer process.

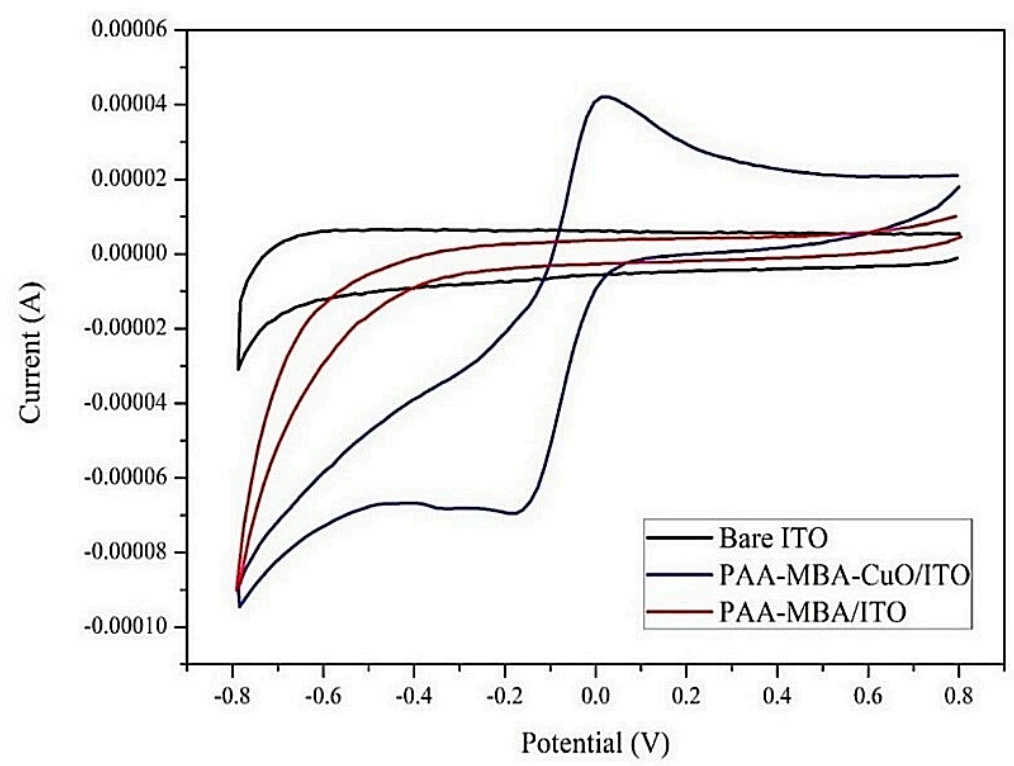

Figure 5. Cyclic voltammograms of the bare ITO, MBA-PAA/ITO, and CuO-MBA-PAA electrode in $0.1 \mathrm{M}$ phosphate buffer solution (PBS) $(\mathrm{pH}=7.4)$.

\subsubsection{Feasibility Analysis of Electrochemical $\mathrm{H}_{2} \mathrm{O}_{2}$ Detection}

The electrocatalytic activity of the CuO-PAA-MBA/ITO electrode toward the $\mathrm{H}_{2} \mathrm{O}_{2}$ reduction was evaluated in $0.1 \mathrm{M}$ PBS ( $\mathrm{pH}=7.4$ ) with a scan rate of $100 \mathrm{mV} / \mathrm{s}$ for various concentrations of $\mathrm{H}_{2} \mathrm{O}_{2}$. The reduction current of the CuO-PAA-MBA/ITO electrode (Figure 6) greatly increased with increasing concentrations of $\mathrm{H}_{2} \mathrm{O}_{2}$. The result confirmed that the CuO-PAA-MBA/ITO electrode showed good electrochemical response for the detection of $\mathrm{H}_{2} \mathrm{O}_{2}$ over a wide concentration range, indicating a good electrocatalytic behavior of CuO-PAA-MBA/ITO towards $\mathrm{H}_{2} \mathrm{O}_{2}$ reduction.

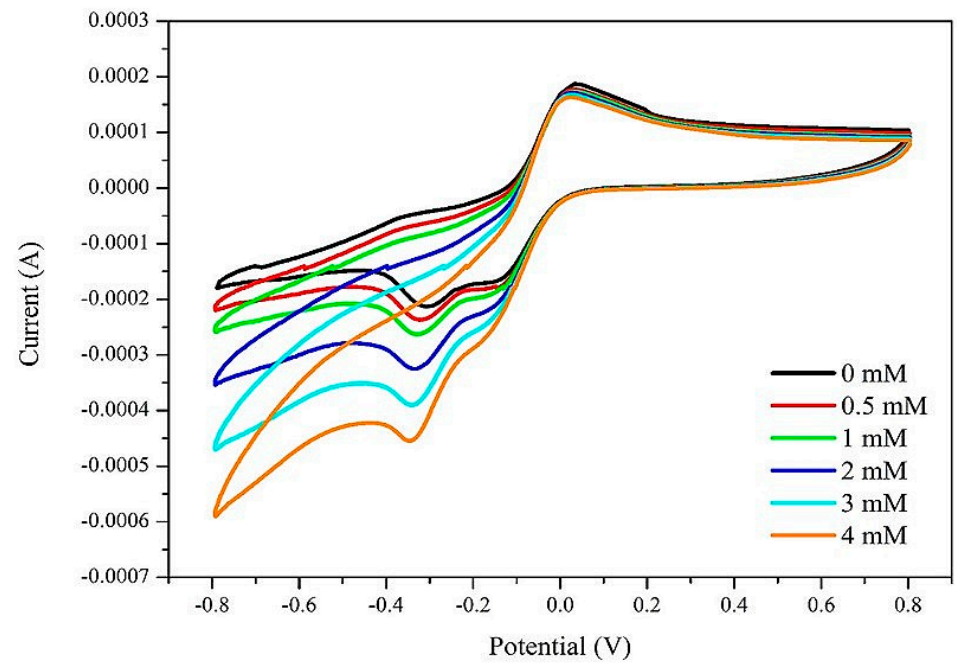

Figure 6. Cyclic voltammograms of the $\mathrm{CuO}-\mathrm{MBA}-\mathrm{PAA} / \mathrm{ITO}$ electrode with different concentrations of $\mathrm{H}_{2} \mathrm{O}_{2}$ at scan rate $100 \mathrm{mV} / \mathrm{s}$ in $0.1 \mathrm{M}$ PBS $(\mathrm{pH}=7.4)$. 


\subsubsection{Amperometric $\mathrm{H}_{2} \mathrm{O}_{2}$ Detection and Sensor Performances}

The amperometric analysis was used to evaluate the electrocatalytic activity of the $\mathrm{CuO}-\mathrm{PAA}(\mathrm{MBA}) / \mathrm{ITO}$ electrode for different concentrations of $\mathrm{H}_{2} \mathrm{O}_{2}$. Figure 7 displays the steady state amperometric response of the CuO-PAA-MBA/ITO electrode for successive additions of $\mathrm{H}_{2} \mathrm{O}_{2}$ into a continuously stirred $0.1 \mathrm{M}$ PBS solution $(\mathrm{pH}=7.4)$ at an applied potential of $-0.4 \mathrm{~V}$. Upon adding $0.5 \mathrm{mM} \mathrm{H}_{2} \mathrm{O}_{2}$, the amperometric current of the CuO-PAA-MBA/ITO electrode reached a steady state current value within $5 \mathrm{~s}$ indicating rapid and sensitive response of the electrode towards electrocatalytic reduction of $\mathrm{H}_{2} \mathrm{O}_{2}$. We observed that the amperometric current values increased with increasing concentration of $\mathrm{H}_{2} \mathrm{O}_{2}$. A good linear relationship between current and concentration of $\mathrm{H}_{2} \mathrm{O}_{2}$ was obtained in the range from 0.5 to $8.5 \mathrm{mM}$ with a detection limit of $0.6 \mu \mathrm{M}(\mathrm{S} / \mathrm{N}=3)$. The sensitivity of the fabricated catalytic electrode was estimated as $63.52 \mathrm{~mA} \mathrm{M}^{-1} \mathrm{~cm}^{-2}$.
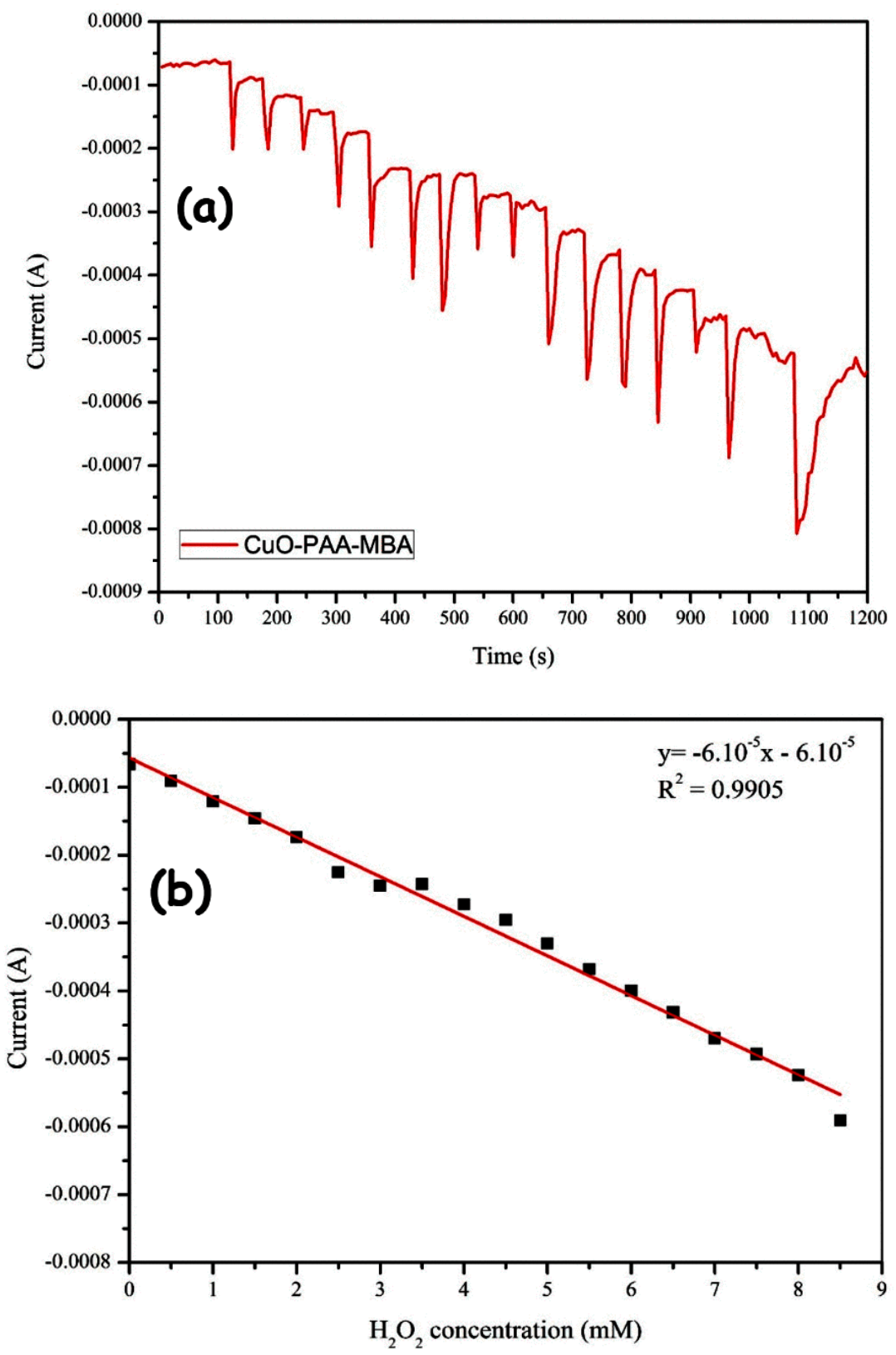

Figure 7. Amperometric response of the CuO-MBA-PAA/ITO electrode by addin $\mathrm{H}_{2} \mathrm{O}_{2}$ in $0.1 \mathrm{M}$ PBS at $-0.4 \mathrm{~V}$ (left side) and the detection calibration curves by adding $\mathrm{H}_{2} \mathrm{O}_{2}$ (right side). 


\subsubsection{Selectivity Measurement of the Fabricated Catalytic Electrode}

Selectivity is one of the most crucial factors that needs to be considered while fabricating an electrochemical sensor for a selected analyte. In this study, the selectivity of the catalytic electrode with $\mathrm{CuO}$ NPs was evaluated in the presence of three electrochemical interfering substances for $\mathrm{H}_{2} \mathrm{O}_{2}$, namely sodium chloride, ascorbic acid, and sodium nitrite, at the $0.1 \mathrm{mM}$ level, respectively (Figure 8). As can be seen in Figure 8, the current value of CuO-PAA-MBA/ITO electrode is not significantly influenced in the presence of any of the three selected interfering substances. These results indicate that the CuO-PAA(MBA)/ITO electrode, has a good selectivity towards the detected $\mathrm{H}_{2} \mathrm{O}_{2}$.

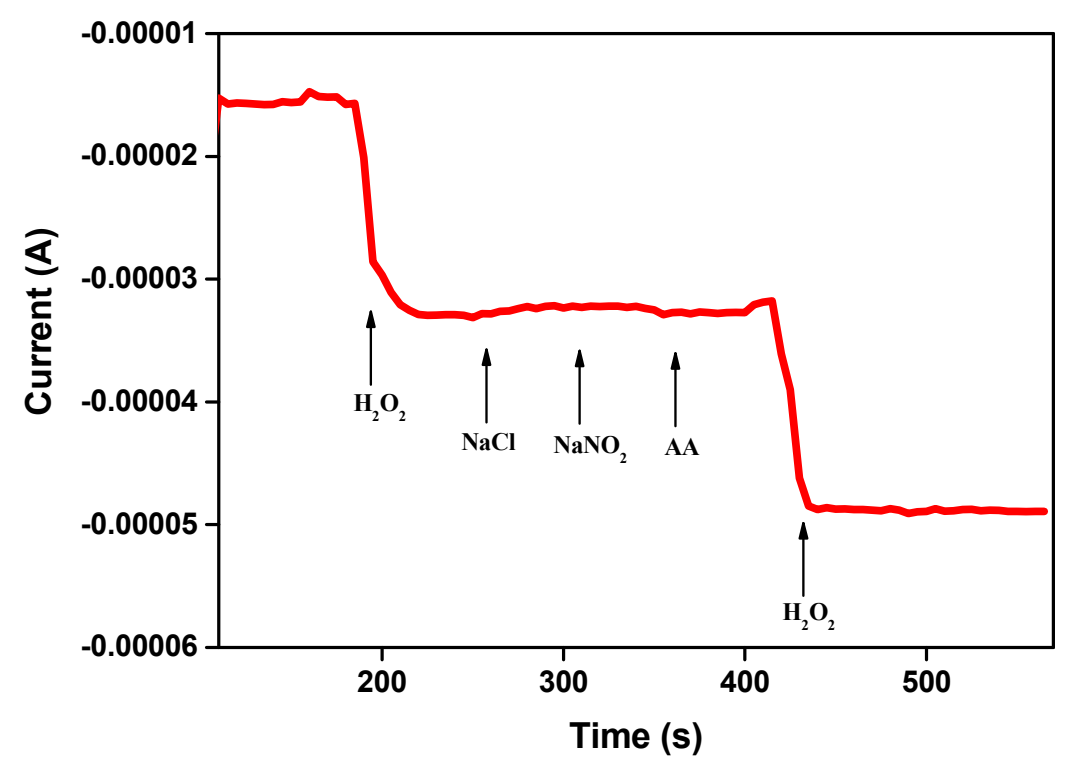

Figure 8. Selectivity of CuO-MBA-PAA/ITO electrode.

It is known that oxygen is an another important interferent during the reduction process of $\mathrm{H}_{2} \mathrm{O}_{2}$. Hence, the supporting electrolyte needs to be de-oxygenated by bubbling nitrogen for sufficient length of time ( $20 \mathrm{~min})$ to avoid the most common possible interferents, namely dissolved oxygen in the electrolyte system [41]. Importantly, in the present work, the reduction potential of $\mathrm{H}_{2} \mathrm{O}_{2}$ on $\mathrm{CuO}-\mathrm{PAA}-\mathrm{MBA} / \mathrm{ITO}$ electrode was around $-0.4 \mathrm{~V}$, which is far beneath the thermodynamic electrode potential for oxygen reduction at standard conditions. Hence, the interference from oxygen is negligible in this work. All the above results have indicated that the proposed $\mathrm{H}_{2} \mathrm{O}_{2}$ sensor could be used in vivo measurements.

\subsubsection{Stability Measurement of the Fabricated Catalytic Electrode}

The stability of the CuO-PAA(MBA)/ITO electrode towards detection of $\mathrm{H}_{2} \mathrm{O}_{2}$ was investigated by $\mathrm{CVs}$ by monitoring the reduction current of $0.5 \mathrm{mM} \mathrm{H}_{2} \mathrm{O}_{2}$ for different numbers of cycles. As shown in Figure 9, the reduction current value of the catalytic electrode showed a marginal difference for initial cycles but decreased by $23 \%$ after 120 cycles. The stable peak currents at the initial cycles is acceptable for a practical sensor. The decrease in current after a large number of continuous cycles $(>100)$ may be due to the leaching of $\mathrm{CuO}$ from the electrode surface. Continuously keeping the electrode at a longer period during the experiment may be the reason for the leaching of catalytically active material from the electrode surface. Further optimization of the PAA (MBA) forming condition could possibly avoid the problem related to leaching of catalytically active particle from the electrode surface. 


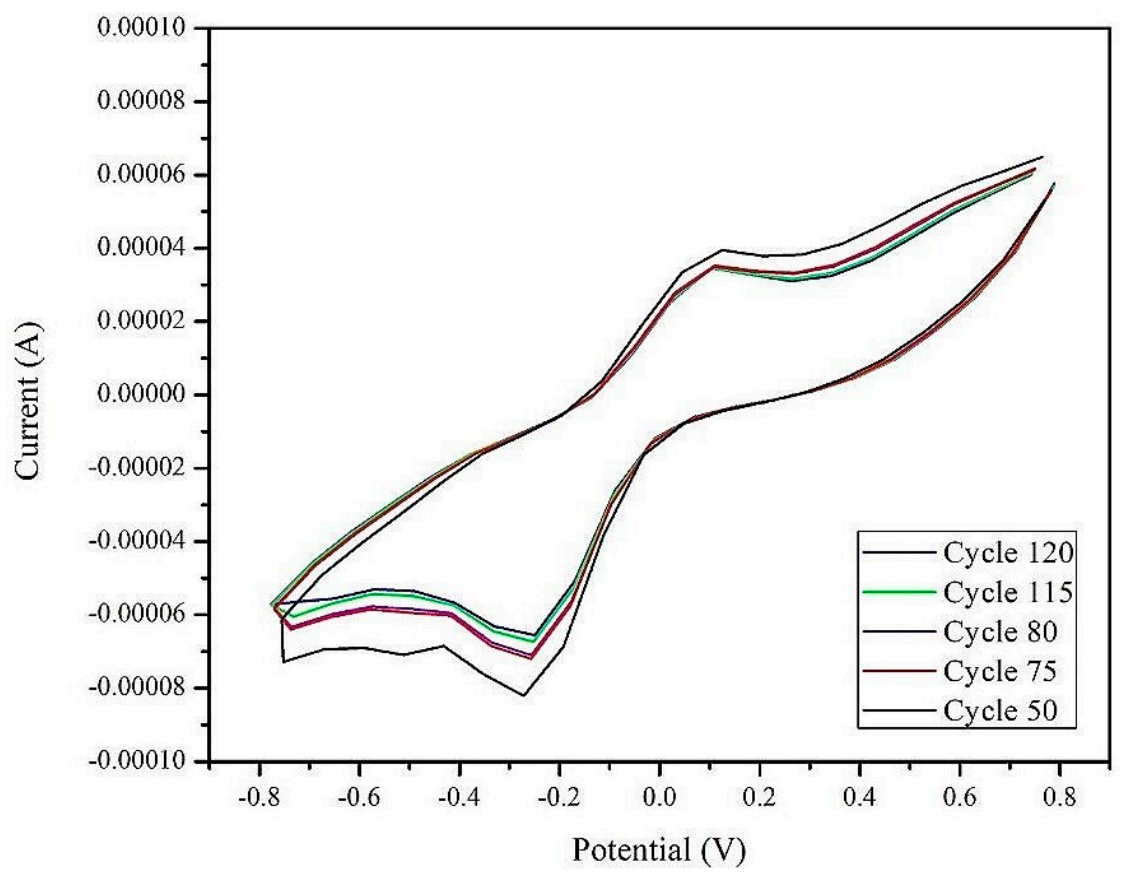

Figure 9. Stability of CuO-MBA-PAA/ITO electrode.

\section{Discussion}

\section{Electrode Fabrication by Plasma Treatment}

In the case of PAA/ITO and PAA (MBA)/ITO electrode fabrication through plasma treatment, we envisage the deposition of polymer layer on ITO through the following sequence of reactions. Initially, the physical state of vinyl monomer (AA) or mixture of AA and MBA, upon treatment of plasma, changes from liquid state to vapor phase (Figure 10). Subsequently, the formation of reactive fragments, such as radicals from the vinyl monomer(s) and conversion of them to polymer are expected to happen in the gas phase. The polymer (PAA or PAA(MBA)) is deposited on the ITO surface, thus creating a plasma-deposited polymer coating on the surface. Since the vinyl monomer is fragmented in the plasma, the created polymer layer will not necessarily have a structure and composition which is similar to polymers achieved by conventional polymerization of the same monomer. Plasma polymerization can take place with many monomers in the vapor phase, even if they do not have unsaturated bonds or cyclic structures. The use of MBA along with generates a network, PAA (MBA), which was eventually deposited on the entire surface of the ITO [28].

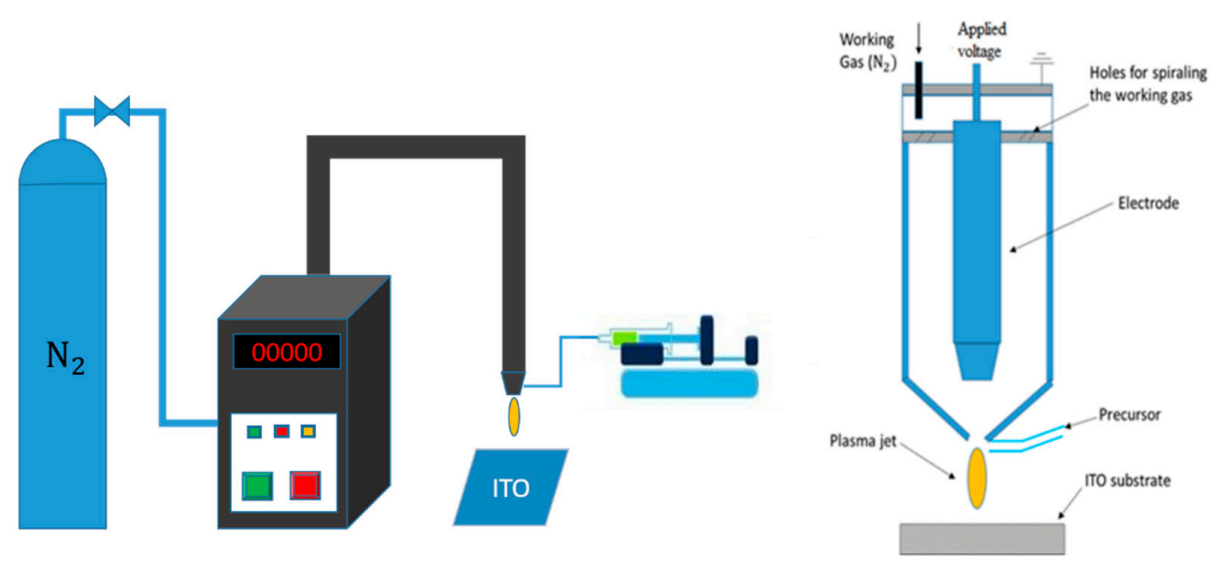

Figure 10. Schematic diagram of the AC plasma deposition process. 
The precursor solution for the metal oxide/PAA or metal oxide/PAA(MBA) deposition contained either a mixture of acrylic acid and the respective salts, or acrylic acid, cross-linking agent (MBA), and the respective salts as in Table 1. Complexes of polymers derived from natural amino acids or carboxylic-containing polymers such as PAA with various charge density along the main chain, have been extensively studied [42]. Based on that, we envisage there could be possibility for the formation of complexes between metal salts or the polymer after the plasma treatment. Keeping the fact that the primary coordination number of the divalent metals used in this work is predominantly four, we presume that PAA-divalent metal complexes could be a square planar or tetrahedral structure as proposed earlier [42]. In the complexation proposal, the two coordination sites of the metal ion can be satisfied by the two carboxyl anions, and the residual two coordination sites can be satisfied by the oxygen of two carboxyl groups in the polymer. In our case, our goal was to fabricate a modified electrode. The plasma treatment, as we have used in this work, was favorably used to fabricate the metal oxide anchored PAA or PAA(MBA)-based electrodes. However, in the case of metal oxide/PAA/ITO electrode, the metal oxide was found to be leached out. Hence, we presume that the removal of metal ions from the complexes could be possible when the PAA structure favors planar complexes. On the other hand, the electrochemical stability of metal oxide/PAA(MBA) electrode was superior (Figure 4). We therefore envisage that the three-dimensional polymer network generated by MBA can facilitate three-dimensional interlocked metal ions within PAA(MBA) and could be the reason for the extended stability for metal oxide/PAA(MBA)/ITO over metal oxide/PAA electrodes.

Table 1. Precursors and experimental conditions used for AC plasma deposition onto ITO surface.

\begin{tabular}{|c|c|c|c|c|c|c|}
\hline \multirow{2}{*}{ Reagents } & \multicolumn{4}{|c|}{ A-Type } & \multicolumn{2}{|c|}{ B-Type } \\
\hline & PAA & CuO-PAA & $\mathrm{Fe}_{2} \mathrm{O}_{3}$-PAA & ZnO-PAA & MBA-PAA & CuO-MBA-PAA \\
\hline $\mathrm{CuCl}_{2} \cdot 2 \mathrm{H}_{2} \mathrm{O}$ & - & $0.2 \mathrm{mM}$ & - & - & - & $0.2 \mathrm{mM}$ \\
\hline $\mathrm{FeCl}_{3} \cdot 6 \mathrm{H}_{2} \mathrm{O}$ & - & - & $0.2 \mathrm{mM}$ & - & - & - \\
\hline $\mathrm{ZnCl}_{2} \cdot 2 \mathrm{H}_{2} \mathrm{O}$ & - & - & - & $0.2 \mathrm{mM}$ & - & - \\
\hline MBA & & & - & & $0.5 \mathrm{~g}$ & $0.5 \mathrm{~g}$ \\
\hline $\mathrm{H}_{2} \mathrm{O}$ & - & $0.5 \mathrm{~mL}$ & $0.5 \mathrm{~mL}$ & $0.5 \mathrm{~mL}$ & - & $0.5 \mathrm{~mL}$ \\
\hline AA & $5.0 \mathrm{~mL}$ & $5.0 \mathrm{~mL}$ & $5.0 \mathrm{~mL}$ & $5.0 \mathrm{~mL}$ & $5.0 \mathrm{~mL}$ & $5.0 \mathrm{~mL}$ \\
\hline
\end{tabular}

In plasma environments, the metal oxide NPs could be formed and included in PAA(MBA) film. A schematic presentation is shown in Figure 11 that presents how electrocatalytic reduction of $\mathrm{H}_{2} \mathrm{O}_{2}$ at the $\mathrm{CuO}-\mathrm{PAA}(\mathrm{MBA}) / \mathrm{ITO}$ electrode could be used for the fabrication of sensor electrodes. The mechanism comprises the electrochemical reduction of $\mathrm{CuO}(\mathrm{Cu}(\mathrm{II})$ state) to $\mathrm{Cu} 2 \mathrm{O}(\mathrm{Cu}(\mathrm{I})$ state), which subsequently converts $\mathrm{H}_{2} \mathrm{O}_{2}$ to a hydroxyl ion or water along with the regeneration of the catalyst [43].
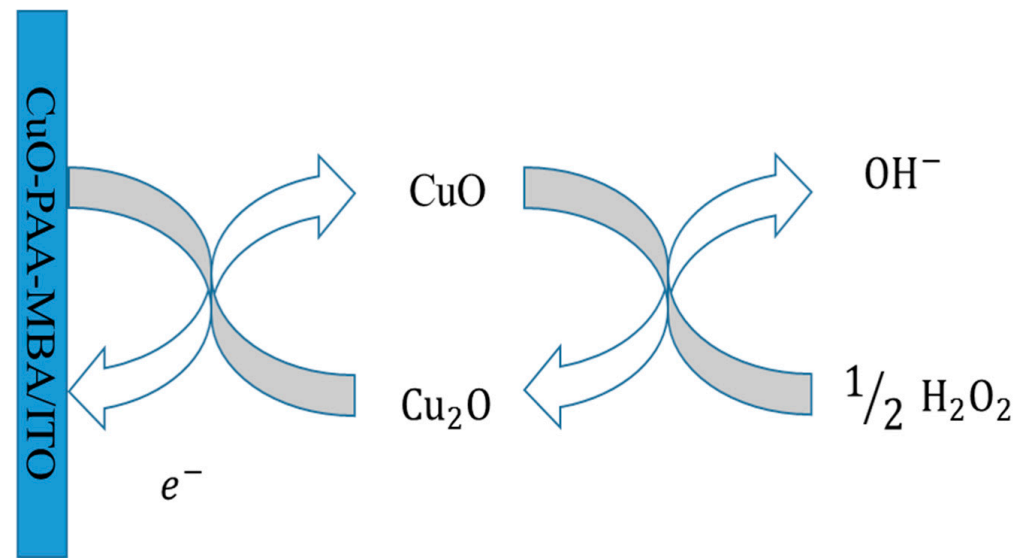

Figure 11. A plausible mechanism for the electrocatalytic reduction of $\mathrm{H}_{2} \mathrm{O}_{2}$ at the CuO-loaded ITO electrode. 
Table 2 provides the summary of fabricated $\mathrm{CuO}$-modified sensors and preparation conditions of $\mathrm{CuO}$-loaded ITO electrodes. In brief, the $\mathrm{CuO}$-loaded ITO electrode exhibits a wider linear range $(0.5-8.5 \mathrm{mM})$, a lowest detection limit $(0.6 \mu \mathrm{M})$ and high sensitivity $\left(63.52 \mathrm{~mA} \mathrm{M}^{-1} \mathrm{~cm}^{-2}\right)$ for the electrochemical detection of $\mathrm{H}_{2} \mathrm{O}_{2}$. The fabrication of CuO-loaded electrode is simple (one-step AC plasma deposition) and easy to prepare.

Table 2. Electrocatalytic sensor based on the $\mathrm{CuO}$ nanostructure prepared by various preparation methods.

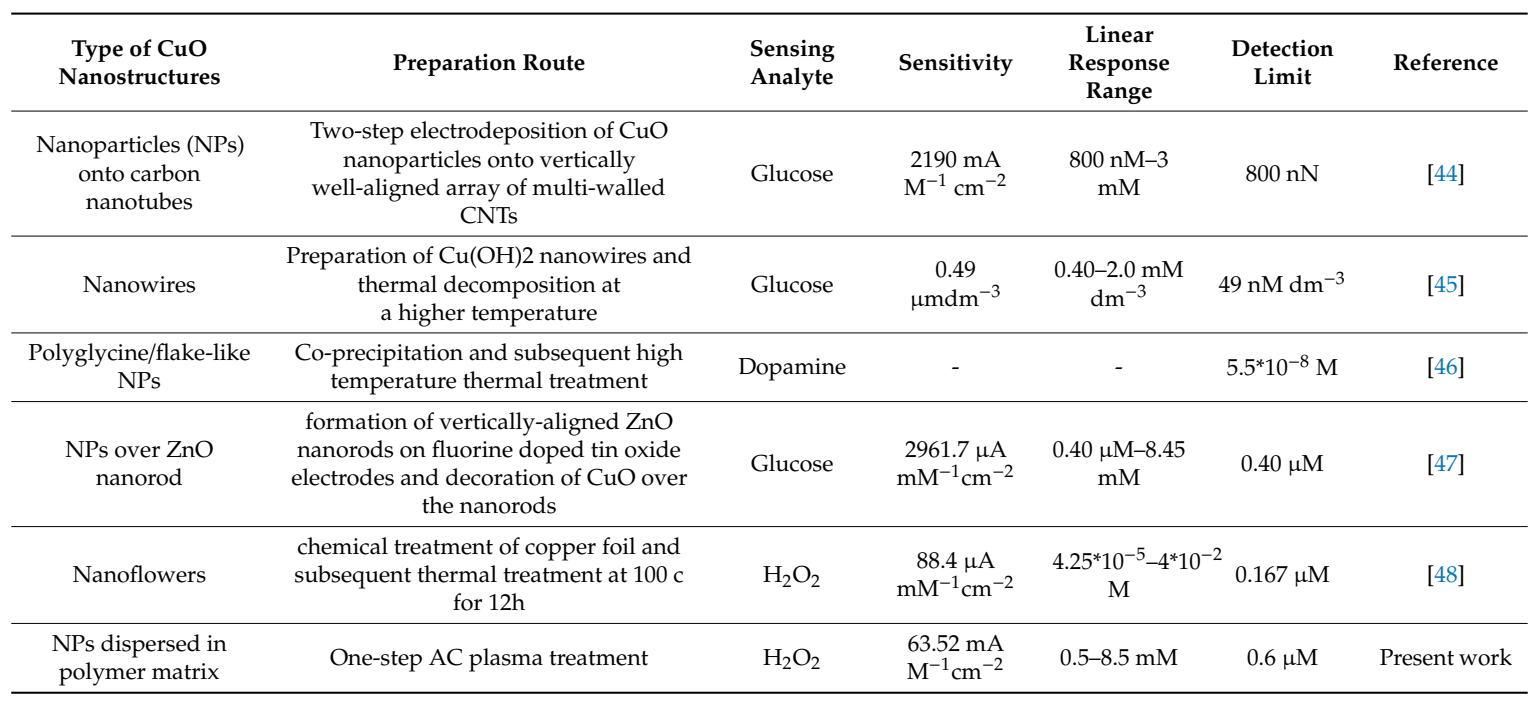

\section{Materials and Methods}

\subsection{Reagents}

(MBA, copper (II) chloride dihydrate, iron (III) chloride hexahydrate, zinc (II) chloride dehydrate, ascorbic acid, sodium chloride, sodium hydroxide, uric acid, sodium phosphate monobasic dihydrate $\left(\mathrm{NaH}_{2} \mathrm{PO}_{4} \cdot 2 \mathrm{H}_{2} \mathrm{O}\right)$, and sodium phosphate dibasic dihydrate $\left(\mathrm{Na}_{2} \mathrm{HPO}_{4} \cdot 2 \mathrm{H}_{2} \mathrm{O}\right)$ were purchased from Sigma Aldrich (Sigma-Aldrich, St. Louis, MO, USA). Potassium chloride, potassium ferrocyanide $\left(\mathrm{K}_{4} \mathrm{Fe}(\mathrm{CN})_{6} \cdot 3 \mathrm{H}_{2} \mathrm{O}\right)$, potassium ferricyanide $\left(\mathrm{K}_{3} \mathrm{Fe}(\mathrm{CN})_{6}\right.$, and hydrogen peroxide $\left(\mathrm{H}_{2} \mathrm{O}_{2}, 30 \%\right)$ were purchased from Duksan Pharmaceutical Co., Ltd. (Ansan, Korea). Acrylic acid and hydrochloric acid were supplied by Alfa Aesar (Ward Hill, MA, USA). Indium tin oxide (ITO)-coated glass as working electrode $(25 \mathrm{~mm} \times 25 \mathrm{~mm} \times 1.1 \mathrm{~mm}, 30-60 \Omega / \mathrm{sq})$ was purchased from Sigma Aldrich Co. (Sigma-Aldrich, St. Louis, MO, USA). Phosphate buffer solution (PBS) was prepared by mixing of $0.1 \mathrm{M}$ $\mathrm{Na}_{2} \mathrm{HPO}_{4}$ and $0.1 \mathrm{M} \mathrm{NaH}_{2} \mathrm{PO}_{4}$, and then adjusted $\mathrm{pH}$ to the value of 7.4. Solutions for the experiments were prepared with water purification by a Milli-Q plus water purification system (Millipore Co. Ltd., Burlington, MA, USA, the final resistance of water was $18.2 \mathrm{M} \Omega \mathrm{cm}^{-1}$ ).

\subsection{Instruments}

FT-IR spectra were obtained using a Nicolet iS10 (Thermo Fisher Scientific Inc., Walttham, MA, USA). Surface properties were characterized by contact angle (PHOENIX- 300, Surface Electro Optics Co., Ltd., Suwon, Korea), scanning electron microscopy (FE-SEM (S-4800), Hitachi, Tokyo, Japan), and X-ray photoelectron spectroscopy (MultiLab. ESCA 2000, Thermo Fisher Scientific Inc., Walttham, MA, USA). Cyclic voltammetry (CV) was performed using a VersaSTAT 3 potentiostat/galvanostat (AMETEK PAR, Berwyn, PA, USA) and a conventional three-electrode system comprising an ITO glass as working electrode, a platinum wire as counter electrode, and an $\mathrm{Ag} / \mathrm{AgCl}$ (saturated $\mathrm{KCl}$ ) as reference electrode.

Plasma devices were required to be small, simple, and portable for various applications. We chose an AC-type plasma device that is closest to these requirements, and the power can be controlled in 
the range of 200 to $250 \mathrm{~W}$. Most of the experiments were carried out in the region of $200 \mathrm{~W}$. Torches used in this experiment were conical and the diameter of the torch tip was $2.0 \mathrm{~mm}$. Nitrogen as the working gas was supplied from a tank connected to the plasma generator and a flow controller inside. The plasma generator was used to keep the pressure at a constant level. The stock solution was injected to the AC plasma jet by a syringe pump in a down-stream region. ITO substrate was placed under the AC plasma jet at a distance of $1 \mathrm{~cm}$ and could be moved manually during the deposition process as shown in Figure 10.

\subsection{Fabrication of Catalytic Electrode by AC Plasma Deposition}

The precursor solutions for the experiment were prepared as follows. Firstly, a precise amount of a metal salt was dissolved in $0.5 \mathrm{~mL}$ purified water, then mixed with $5 \mathrm{~mL}$ of acrylic acid. Three metal salts, namely copper (II) chloride, ion (III) chloride, and zinc (II) chloride were used in this experiment. A blank sample which has only acrylic acid was also prepared for comparison. The suggested amounts of those precursor solution are shown in Table 1.

ITO substrate was pre-cleaned using ethanol and ultra-sonicated for $10 \mathrm{~min}$ before AC plasma deposition. During the deposition process, the ITO substrate was moved slowly in the $x$ and $y$ directions and the deposition time was five minutes. The precursor solutions were injected into the AC plasma jet by the syringe pump at a flow rate of $0.3 \mathrm{~mL} / \mathrm{min}$ and the gas pressure was kept constantly at 0.018 MPa. After the deposition processes finished, the fabricated electrodes were cleaned with water and methanol to remove the unreacted precursors then dried and stored at $4{ }^{\circ} \mathrm{C}$ before application.

\section{Conclusions}

A metal oxide $(\mathrm{CuO})$ dispersed catalytic electrode was successfully fabricated by a one-step AC plasma deposition method, and further utilized for the electrochemical detection of hydrogen peroxide $\left(\mathrm{H}_{2} \mathrm{O}_{2}\right)$. Polymer and metal oxide were simultaneously formed on the electrode surface, thus making the modified electrode fabrication simple. The stability of the polymer-metal oxide modified surface can be made electrochemically stable through a cross-linking process during plasma treatment. Our results indicated that electrochemical sensing of $\mathrm{H}_{2} \mathrm{O}_{2}$ could be achieved through electrocatalytic reduction with a reasonable sensitivity, selectivity and stability. More importantly, the simple strategy, namely plasma treatment of relevant precursors, which we used in this work, could be conveniently extended to the fast and simple fabrication of electrochemical sensors based on other kinds of nanomaterials (example: metallic nanoparticles).

Supplementary Materials: The following are available online at http://www.mdpi.com/2073-4344/9/11/888/s1, Figure S1: EDS of the bare (a) ITO, (b) PAA, (c) CuO-PAA, (d) $\mathrm{Fe}_{2} \mathrm{O}_{3}-\mathrm{PAA}$ and (e) ZnO-PAA/ITO electrodes, Figure S2: XPS spectra of the bare ITO (a), PAA (b), CuO-PAA (c), $\mathrm{Fe}_{2} \mathrm{O}_{3}$-PAA (d) and ZnO-PAA/ITO electrodes (e), Figure S3: XPS spectra of (a) MBA-PAA and (b) CuO-MBA-PAA/ITO electrode.

Author Contributions: Q.-T.B. and I.-K.Y.-Conceptualization, experimentation, writing: A.I.G.-Conceptualization, methodology, data interpretation and writing; G.S.-Data analysis/interpretation, review and editing; W.K. and S.-H.C.- Supervision, project administration, funding acquisition and constructive suggestions.

Funding: This research was supported by the Korea Environment Industry and Technology Institute (KEITI) through Technology Development Programs for Environmental Industry Advancement, funded by the Korea Ministry of Environment (MOE) (E318-00012-0807-01).

Conflicts of Interest: The authors declare no conflict of interest.

\section{References}

1. Freakley, S.J.; He, Q.; Harrhy, J.H.; Lu, L.; Crole, D.A.; Morgan, D.J.; Ntainjua, E.N.; Edwards, J.K.; Carley, A.F.; Borisevich, A.Y.; et al. Palladium-tin catalysts for the direct synthesis of $\mathrm{H}_{2} \mathrm{O}_{2}$ with high selectivity. Science 2016, 351, 965-968. [CrossRef] [PubMed] 
2. Yi, Y.; Wang, L.; Li, G.; Guo, H. A review on research progress in the direct synthesis of hydrogen peroxide from hydrogen and oxygen: Noble-metal catalytic method, fuel-cell method and plasma method. Catal. Sci. Technol. 2016, 6, 1593-1610. [CrossRef]

3. Benzigar, M.R.; Joseph, S.; Saianand, G.; Gopalan, A.-I.; Sarkar, S.; Srinivasan, S.; Park, D.-H.; Kim, S.; Talapaneni, S.N.; Ramadass, K.; et al. Highly ordered iron oxide-mesoporous fullerene nanocomposites for oxygen reduction reaction and supercapacitor applications. Microporous Mesoporous Mater. 2019, 285, $21-31$. [CrossRef]

4. Anantha-Iyengar, G.; Shanmugasundaram, K.; Nallal, M.; Lee, K.-P.; Whitcombe, M.J.; Lakshmi, D.; Sai-Anand, G. Functionalized conjugated polymers for sensing and molecular imprinting applications. Prog. Polym. Sci. 2019, 88, 1-129. [CrossRef]

5. Sai-Anand, G.; Sivanesan, A.; Benzigar, M.R.; Singh, G.; Gopalan, A.-I.; Baskar, A.V.; Ilbeygi, H.; Ramadass, K.; Kambala, V.; Vinu, A. Recent Progress on the sensing of pathogenic bacteria using advanced nanostructures. Bull. Chem. Soc. Jpn. 2019, 92, 216-244. [CrossRef]

6. Komathi, S.; Gopalan, A.I.; Kim, S.-K.; Anand, G.S.; Lee, K.-P. Fabrication of horseradish peroxidase immobilized poly (N-[3-(trimethoxy silyl) propyl]aniline) gold nanorods film modified electrode and electrochemical hydrogen peroxide sensing. Electrochim. Acta 2013, 92, 71-78. [CrossRef]

7. Gopalan, A.I.; Komathi, S.; Sai Anand, G.; Lee, K.-P. Nanodiamond based sponges with entrapped enzyme: A novel electrochemical probe for hydrogen peroxide. Biosens. Bioelectron. 2013, 46, 136-141. [CrossRef]

8. Shanmugasundaram, K.; Sai-Anand, G.; Gopalan, A.-I.; Lee, H.-G.; Yeo, H.K.; Kang, S.-W.; Lee, K.-P. Direct electrochemistry of cytochrome $\mathrm{c}$ with three-dimensional nanoarchitectured multicomponent composite electrode and nitrite biosensing. Sens. Actuators B Chem. 2016, 228, 737-747. [CrossRef]

9. Sai-Anand, G.; Gopalan, A.-I.; Kang, S.-W.; Komathi, S.; Lee, K.-P. One pot synthesis of new gold nanoparticles dispersed poly (2-aminophenyl boronic acid) composites for fabricating an affinity based electrochemical detection of glucose. Sci. Adv. Mater. 2014, 6, 1356-1364. [CrossRef]

10. Thunkhamrak, C.; Chuntib, P.; Ounnunkad, K.; Banet, P.; Aubert, P.-H.; Saianand, G.; Gopalan, A.-I.; Jakmunee, J. Highly sensitive voltammetric immunosensor for the detection of prostate specific antigen based on silver nanoprobe assisted graphene oxide modified screen printed carbon electrode. Talanta 2019, 208, 120389. [CrossRef]

11. Kang, B.-H.; Kim, J.-S.; Lee, J.-S.; Lee, S.-W.; Sai-Anand, G.; Jeong, H.-M.; Lee, S.-H.; Kwon, D.-H.; Kang, S.-W. Solution processable $\mathrm{CdSe} / \mathrm{ZnS}$ quantum dots light-emitting diodes using $\mathrm{ZnO}$ nanocrystal as electron transport layer. J. Nanosci. Nanotechnol. 2015, 15, 7416-7420. [CrossRef] [PubMed]

12. Lee, H.-G.; Gopalan, A.-I.; Sai-Anand, G.; Lee, B.-C.; Kang, S.-W.; Lee, K.-P. Facile synthesis of functionalized graphene-palladium nanoparticle incorporated multicomponent $\mathrm{TiO}_{2}$ composite nanofibers. Mater. Chem. Phys. 2015, 154, 125-136. [CrossRef]

13. Lee, S.-W.; Cha, S.-H.; Choi, K.-J.; Kang, B.-H.; Lee, J.-S.; Kim, S.-W.; Kim, J.-S.; Jeong, H.-M.; Gopalan, S.-A.; Kwon, D.-H.; et al. Low dark-current, high current-gain of PVK/ZnO nanoparticles composite-based UV photodetector by PN-heterojunction control. Sensors 2016, 16, 74. [CrossRef] [PubMed]

14. Lee, J.-C.; Gopalan, A.-I.; Sai-Anand, G.; Lee, K.-P.; Kim, W.-J. Preparation of visible light photocatalytic graphene embedded rutile titanium (IV) oxide composite nanowires and enhanced nox removal. Catalysts 2019, 9, 170. [CrossRef]

15. Lee, H.-G.; Sai-Anand, G.; Komathi, S.; Gopalan, A.-I.; Kang, S.-W.; Lee, K.-P. Efficient visible-light-driven photocatalytic degradation of nitrophenol by using graphene-encapsulated $\mathrm{TiO}_{2}$ nanowires. J. Hazard. Mater. 2015, 283, 400-409. [CrossRef]

16. Sai-Anand, G.; Gopalan, A.-I.; Lee, K.-P.; Venkatesan, S.; Qiao, Q.; Kang, B.-H.; Lee, S.-W.; Lee, J.-S.; Kang, S.-W. Electrostatic nanoassembly of contact interfacial layer for enhanced photovoltaic performance in polymer solar cells. Sol. Energy Mater. Sol. Cells 2016, 153, 148-163. [CrossRef]

17. Lee, S.-W.; Choi, K.-J.; Kang, B.-H.; Lee, J.-S.; Kim, S.-W.; Kwon, J.-B.; Gopalan, S.-A.; Bae, J.-H.; Kim, E.-S.; Kwon, D.-H.; et al. Low dark current and improved detectivity of hybrid ultraviolet photodetector based on carbon-quantum-dots/zinc-oxide-nanorod composites. Org. Electron. 2016, 39, 250-257. [CrossRef]

18. Liu, M.; Liu, R.; Chen, W. Graphene wrapped $\mathrm{Cu}_{2} \mathrm{O}$ nanocubes: Non-enzymatic electrochemical sensors for the detection of glucose and hydrogen peroxide with enhanced stability. Biosens. Bioelectron. 2013, 45, 206-212. [CrossRef] 
19. Xu, F.; Deng, M.; Li, G.; Chen, S.; Wang, L. Electrochemical behavior of cuprous oxide-reduced graphene oxide nanocomposites and their application in nonenzymatic hydrogen peroxide sensing. Electrochim. Acta 2013, 88, 59-65. [CrossRef]

20. Jiang, L.-C.; Zhang, W.-D. A highly sensitive nonenzymatic glucose sensor based on CuO nanoparticlesmodified carbon nanotube electrode. Biosens. Bioelectron. 2010, 25, 1402-1407. [CrossRef]

21. Batchelor-McAuley, C.; Du, Y.; Wildgoose, G.G.; Compton, R.G. The use of copper (II) oxide nanorod bundles for the non-enzymatic voltammetric sensing of carbohydrates and hydrogen peroxide. Sens. Actuators $B$ Chem. 2008, 135, 230-235. [CrossRef]

22. Weng, S.; Zheng, Y.; Zhao, C.; Zhou, J.; Lin, L.; Zheng, Z.; Lin, X.J.M.A. CuO nanoleaf electrode: Facile preparation and nonenzymatic sensor applications. Microchim. Acta 2013, 180, 371-378. [CrossRef]

23. Wang, X.; Hu, C.; Liu, H.; Du, G.; He, X.; Xi, Y. Synthesis of CuO nanostructures and their application for nonenzymatic glucose sensing. Sens. Actuators B Chem. 2010, 144, 220-225. [CrossRef]

24. Wang, K.; Dong, X.; Zhao, C.; Qian, X.; Xu, Y. Facile synthesis of Cu2O/CuO/RGO nanocomposite and its superior cyclability in supercapacitor. Electrochim. Acta 2015, 152, 433-442. [CrossRef]

25. Zhang, L.; Li, H.; Ni, Y.; Li, J.; Liao, K.; Zhao, G. Porous cuprous oxide microcubes for non-enzymatic amperometric hydrogen peroxide and glucose sensing. Electrochem. Commun. 2009, 11, 812-815. [CrossRef]

26. Peng, H.; Fangli, Y.; Liuyang, B.; Jinlin, L.; Yunfa, C. Plasma synthesis of large quantities of zinc oxide nanorods. J. Phys. Chem. C 2007, 111, 194-200. [CrossRef]

27. Langereis, E.; Creatore, M.; Heil, S.B.S.; Sanden, M.C.M.v.d.; Kessels, W.M.M. Plasma-assisted atomic layer deposition of Al2O3 moisture permeation barriers on polymers. Appl. Phys. Lett. 2006, 89, 081915. [CrossRef]

28. Ben Salem, D.; Carton, O.; Fakhouri, H.; Pulpytel, J.; Arefi-Khonsari, F. Deposition of water stable plasma polymerized acrylic Acid/MBA organic coatings by atmospheric pressure Air Plasma Jet. Plasma Process. Polym. 2014, 11, 269-278. [CrossRef]

29. Ishida, Y.; Motokane, Y.; Tokunaga, T.; Yonezawa, T. Plasma induced tungsten doping of $\mathrm{TiO}_{2}$ particles for enhancement of photocatalysis under visible light. Phys. Chem. Chem. Phys. 2015, 17, 24556-24559. [CrossRef]

30. Hattori, Y.; Nomura, S.; Mukasa, S.; Toyota, H.; Inoue, T.; Kasahara, T. Synthesis of tungsten trioxide nanoparticles by microwave plasma in liquid and analysis of physical properties. J. Alloys Compd. 2013, 560, 105-110. [CrossRef]

31. Wang, Z.; Wang, Z.; Zhang, H.; Duan, X.; Xu, J.; Wen, Y. Electrochemical sensing application of poly (acrylic acid modified EDOT-co-EDOT): PSS and its inorganic nanocomposite with high soaking stability, adhesion ability and flexibility. RSC Adv. 2015, 5, 12237-12247. [CrossRef]

32. O'Hare, L.-A.; O'Neill, L.; Goodwin, A.J. Anti-microbial coatings by agent entrapment in coatings deposited via atmospheric pressure plasma liquid deposition. Surf. Interface Anal. 2006, 38, 1519-1524. [CrossRef]

33. Nisol, B.; Batan, A.; Dabeux, F.; Kakaroglou, A.; De Graeve, I.; Van Assche, G.; Van Mele, B.; Terryn, H.; Reniers, F. Surface characterization of atmospheric pressure plasma-deposited allyl methacrylate and acrylic acid based coatings. Plasma Process. Polym. 2013, 10, 564-571. [CrossRef]

34. Beck, A.J.; Short, R.D.; Matthews, A. Deposition of functional coatings from acrylic acid and octamethylcyclotetrasiloxane onto steel using an atmospheric pressure dielectric barrier discharge. Surf. Coat. Technol. 2008, 203, 822-825. [CrossRef]

35. Wei, C.; Sun, S.; Mandler, D.; Wang, X.; Qiao, S.Z.; Xu, Z.J. Approaches for measuring the surface areas of metal oxide electrocatalysts for determining their intrinsic electrocatalytic activity. Chem. Soc. Rev. 2019, 48, 2518-2534. [CrossRef]

36. Cao, D.; Chao, J.; Sun, L.; Wang, G. Catalytic behavior of $\mathrm{Co}_{3} \mathrm{O}_{4}$ in electroreduction of $\mathrm{H}_{2} \mathrm{O}_{2}$. J. Power Sources 2008, 179, 87-91. [CrossRef]

37. Polonskyi, O.; Ahadi, A.M.; Peter, T.; Fujioka, K.; Abraham, J.W.; Vasiliauskaite, E.; Hinz, A.; Strunskus, T.; Wolf, S.; Bonitz, M.; et al. Plasma based formation and deposition of metal and metal oxide nanoparticles using a gas aggregation source. Eur. Phys. J. D 2018, 72, 93. [CrossRef]

38. Biesinger, M.C.; Payne, B.P.; Grosvenor, A.P.; Lau, L.W.M.; Gerson, A.R.; Smart, R.S.C. Resolving surface chemical states in XPS analysis of first row transition metals, oxides and hydroxides: $\mathrm{Cr}, \mathrm{Mn}, \mathrm{Fe}, \mathrm{Co}$ and Ni. Appl. Surf. Sci. 2011, 257, 2717-2730. [CrossRef]

39. Ghijsen, J.; Tjeng, L.H.; van Elp, J.; Eskes, H.; Westerink, J.; Sawatzky, G.A.; Czyzyk, M.T. Electronic structure of $\mathrm{Cu}_{2} \mathrm{O}$ and CuO. Phys. Rev. B 1988, 38, 11322-11330. [CrossRef] 
40. Heli, H.; Jafarian, M.; Mahjani, M.G.; Gobal, F. Electro-oxidation of methanol on copper in alkaline solution. Electrochim. Acta 2004, 49, 4999-5006. [CrossRef]

41. Meng, F.; Yan, X.; Liu, J.; Gu, J.; Zou, Z. Nanoporous gold as non-enzymatic sensor for hydrogen peroxide. Electrochim. Acta 2011, 56, 4657-4662. [CrossRef]

42. Tomida, T.; Hamaguchi, K.; Tunashima, S.; Katoh, M.; Masuda, S. Binding properties of a water-soluble chelating polymer with divalent metal ions measured by ultrafiltration. poly (acrylic acid). Ind. Eng. Chem. Res. 2001, 40, 3557-3562. [CrossRef]

43. Miao, X.-M.; Yuan, R.; Chai, Y.-Q.; Shi, Y.-T.; Yuan, Y.-Y. Direct electrocatalytic reduction of hydrogen peroxide based on Nafion and copper oxide nanoparticles modified Pt electrode. J. Electroanal. Chem. 2008, 612, 157-163. [CrossRef]

44. Yang, J.; Jiang, L.-C.; Zhang, W.-D.; Gunasekaran, S. A highly sensitive non-enzymatic glucose sensor based on a simple two-step electrodeposition of cupric oxide $(\mathrm{CuO})$ nanoparticles onto multi-walled carbon nanotube arrays. Talanta 2010, 82, 25-33. [CrossRef] [PubMed]

45. Zhuang, Z.; Su, X.; Yuan, H.; Sun, Q.; Xiao, D.; Choi, M.M.F. An improved sensitivity non-enzymatic glucose sensor based on a $\mathrm{CuO}$ nanowire modified $\mathrm{Cu}$ electrode. Analyst 2008, 133, 126-132. [CrossRef]

46. Reddy, S.; Kumara Swamy, B.E.; Jayadevappa, H. CuO nanoparticle sensor for the electrochemical determination of dopamine. Electrochim. Acta 2012, 61, 78-86. [CrossRef]

47. Ahmad, R.; Tripathy, N.; Ahn, M.-S.; Bhat, K.S.; Mahmoudi, T.; Wang, Y.; Yoo, J.-Y.; Kwon, D.-W.; Yang, H.-Y.; Hahn, Y.-B. Highly efficient non-enzymatic glucose sensor based on $\mathrm{CuO}$ modified vertically-grown $\mathrm{ZnO}$ nanorods on electrode. Sci. Rep. 2017, 7, 5715. [CrossRef]

48. Song, M.-J.; Hwang, S.W.; Whang, D. Non-enzymatic electrochemical CuO nanoflowers sensor for hydrogen peroxide detection. Talanta 2010, 80, 1648-1652. [CrossRef]

(C) 2019 by the authors. Licensee MDPI, Basel, Switzerland. This article is an open access article distributed under the terms and conditions of the Creative Commons Attribution (CC BY) license (http://creativecommons.org/licenses/by/4.0/). 